\title{
Extension of Euskalduna Conference Centre and Concert Hall: A Contemporary Application of Irregular Reciprocal Frames
}

\author{
Alejandro Bernabeu Larena, Prof., PhD, Civil Eng., Technical Univ. of Madrid, Spain; IDOM, Madrid, Spain; \\ David García Ménendez, Civil and Materials Eng., IDOM, Madrid, Spain. Contact: abernabeu@idom.com \\ DOI: $10.2749 / 101686614 X 13830788506233$
}

\begin{abstract}
Reciprocal frame structures, formed by a set of self-supported elements in a closed circuit, have long been used since antiquity to cover large spans with small elements.

The roof structure of the Euskalduna conference centre and concert hall extension in Bilbao, covering an irregular geometry of $3000 \mathrm{~m}^{2}$ with a maximum span of $45 \mathrm{~m}$, presented an interesting opportunity to revisit the concept and to apply these classical systems.
\end{abstract}

Furthermore, its analysis and development led to an interesting discussion on reciprocal frames. They showed great sensitivity of these systems to the local modification of a particular element, establishment of irregular load paths, mobilisation of almost the entire system when locally applying a punctual load and, finally, its large deformability.

Besides, reciprocal frames present particular construction complexities and possibilities due to the moderate length of the structural elements, the predominance of shear-only connections and the necessity of the entire system to be completely erected to guarantee its stability.

Euskalduna extension, completed in 2012, is one of the largest and a very particular case of irregular reciprocal frame structures built in the world. It shows the formal possibilities and potentiality of reciprocal frames to respond to free and irregular geometries.

Keywords: buildings; shell membrane; reciprocal frames; tensile structures; steel; architecture.

\section{Introduction: Roof Structure of the Euskalduna Conference Centre and Concert Hall Extension}

Opened in 1999, Euskalduna conference centre and concert hall in Bilbao quickly

(a)

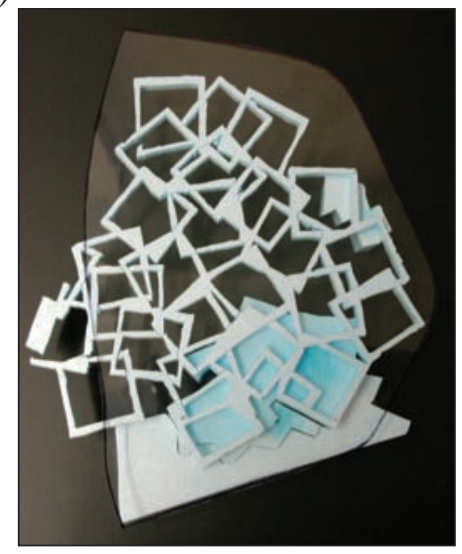

(b)
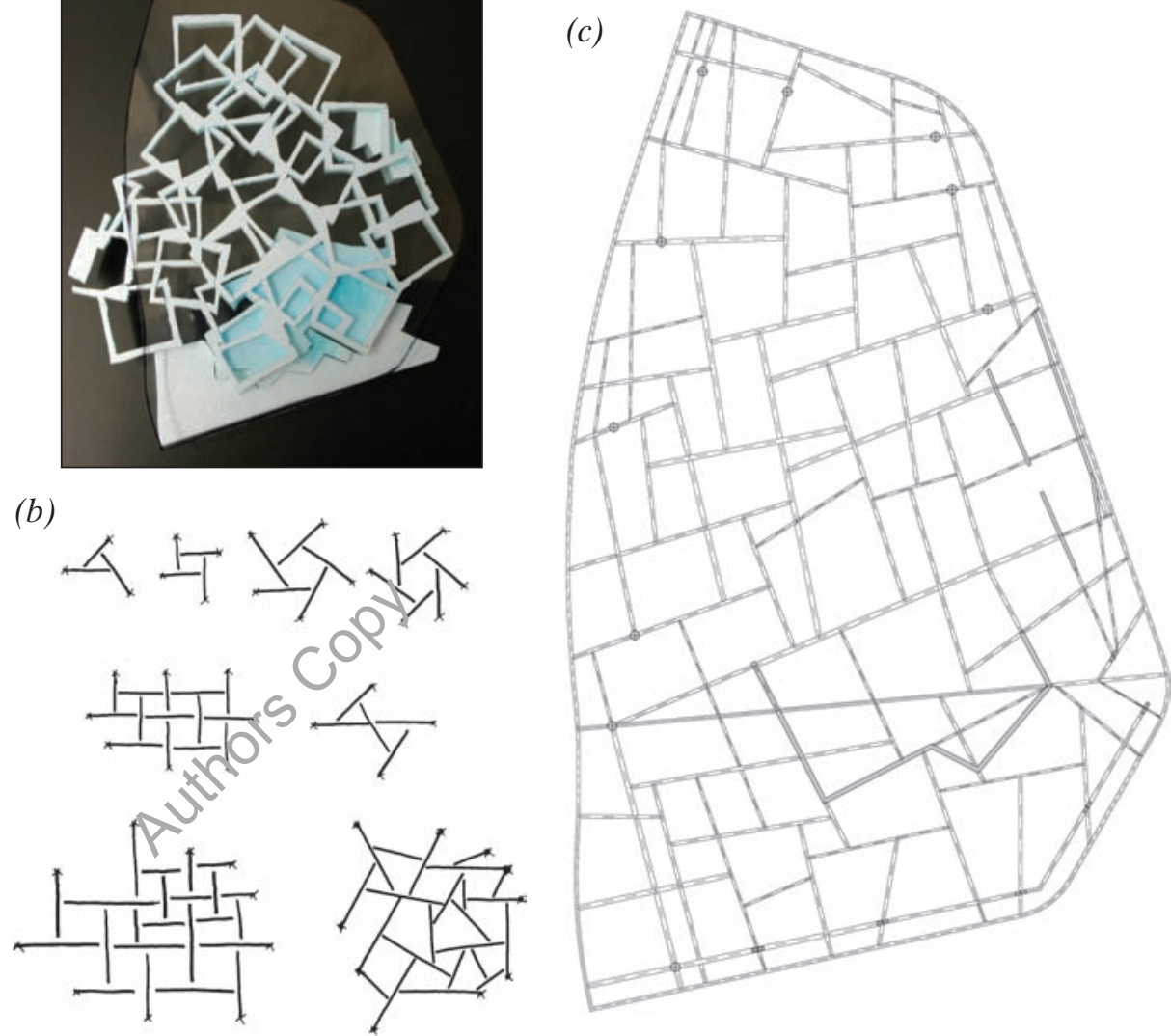

Fig. 1: (a) Architectural working model; (b) principle based on irregular reciprocal frames; (c) final structural configuration

achieved a great popularity, housing a significant number of congresses, concerts and events. ${ }^{1,2}$ As a result of this success and of the high rate of occupation, it was decided to extend the building with a new open-plan area of around $3000 \mathrm{~m},{ }^{2}$ directly connected to the exhibition lobby of the existing building.

The extension is located in the rear esplanade on the east side of the existing building at the ground level. It mainly consists of an irregular openplan exhibition space of about $50 \times 80$ $\mathrm{m}$. This new exhibition area is accessible from the esplanade near the estuary and from the Abandoibarra Avenue, through an intermediate floor level housing offices and service areas.
Together with the facades, the roof quickly acquired a very significant architectural attention as it could be clearly seen from Abandoibarra Avenue due to the prominent slope of the road. Besides, the roof had to cover a main span of about $45 \mathrm{~m}$, freeing the inner space from structural elements, and adjust to a very irregular geometry in plan.

To respond to these conditions, and after considering multiple structural systems and configurations, a solution based on irregular reciprocal frame structures was retained. ${ }^{3}$ This system positively responds to functional requirements and architectural intentions and gives the roof a clear 


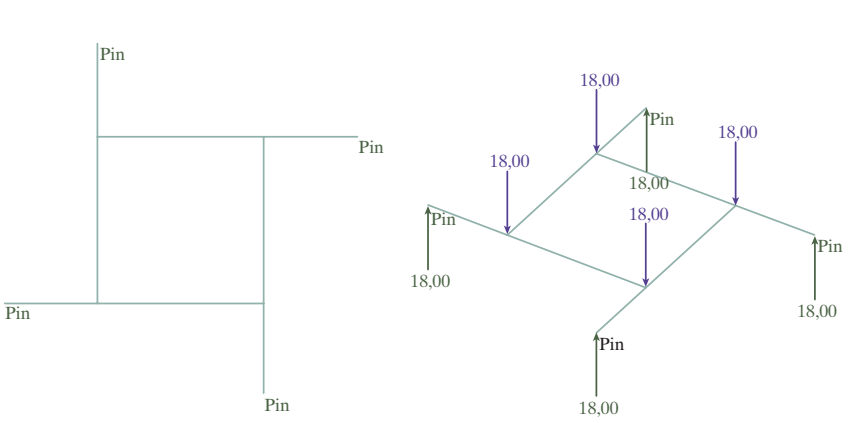

Configuration and supports

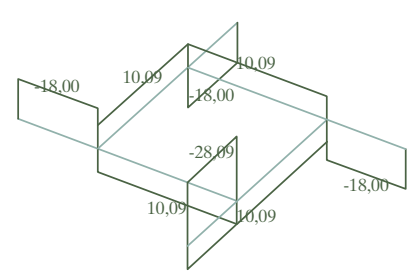

Shear efforts
Loads and reactions

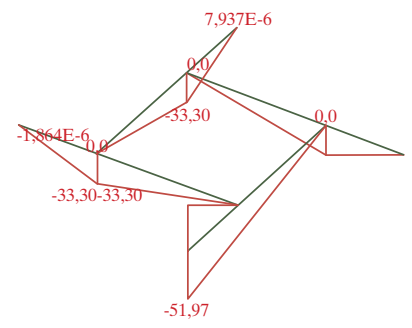

Bending moment efforts

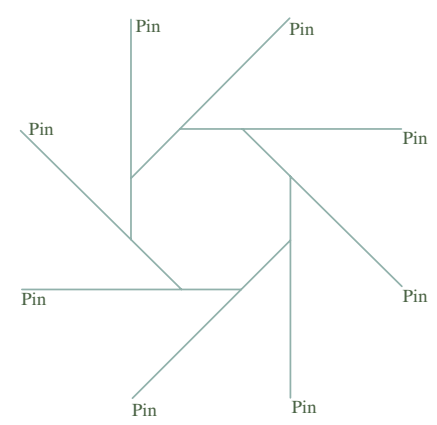

Configuration and supports

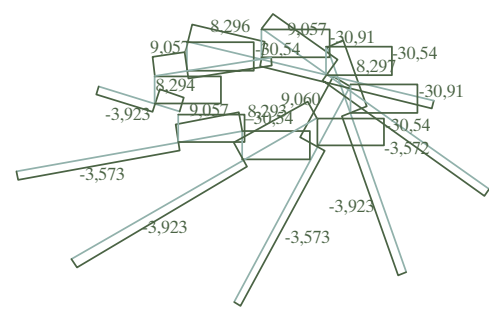

Shear efforts

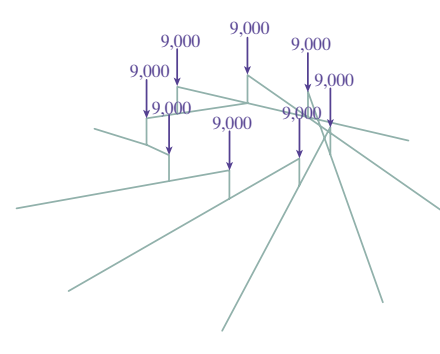

Loads

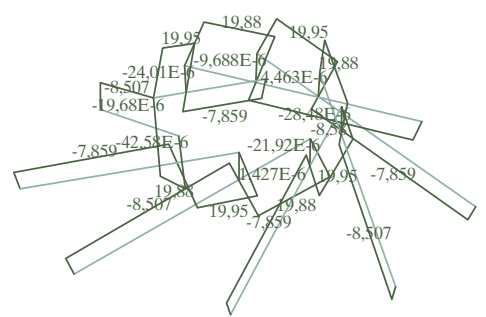

Axial compression efforts

Plane reciprocal frame

Spatial reciprocal frame

Fig. 2: Structural behaviour of reciprocal frames: (a) plane (predominance of bending moments) and (b) spatial (predominance of axial forces)

structural and constructive logic (Fig. 1).

First, the paper briefly presents the principles and precedent references of the reciprocal frame structures and then analyses its application to Euskalduna extension in detail, highlighting its special features in terms of configuration, analysis and construction.

\section{Reciprocal Frame Structures}

Reciprocal frame structures might be defined as a structural system formed by a set of load-bearing elements composing a configuration in which they are mutually supporting one another in a closed circuit. Each element of the configuration, therefore, acts both as support and supporter of other elements, generating a pattern in which all the elements play the same role, without any differences in terms of structural hierarchy. ${ }^{4,5}$ In this sense, they contrast with the other structural systems that are organised following a certain structural hierarchy of the different elements, for example, from primary structure to tertiary structure or substructure. According to this principle, application of a specific load in a particular element is transmitted through the other elements, either as bending moments (plane reciprocal frame) or as axial forces (spatial reciprocal frame), generating a closed circuit that mobilises the entire system
(Fig. 2). These structures are also very sensitive to the type of loading (inplane or out-plane forces) and to the position and type of internati and external constraints.

Although the term peciprocal frame" is very recent (it dates from Graham Brown and Johr Chilton, 1988-19926), the principis of structural reciprocity has been used since antiquity, and evidences of its initial application can be found in Eskimo tents or in Indian tepees. ${ }^{4}$

Later on, its application in Western architecture was mainly due to its capacity to span large distances and to cover large surfaces with smaller elements. At the time, floor structures were built with timber beams supported

(a)

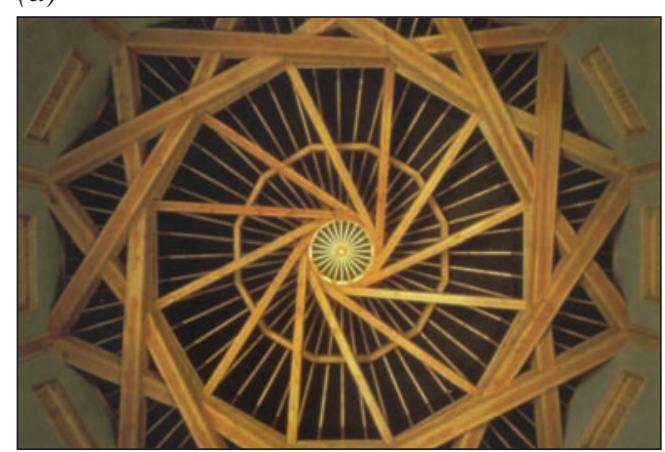

(b)

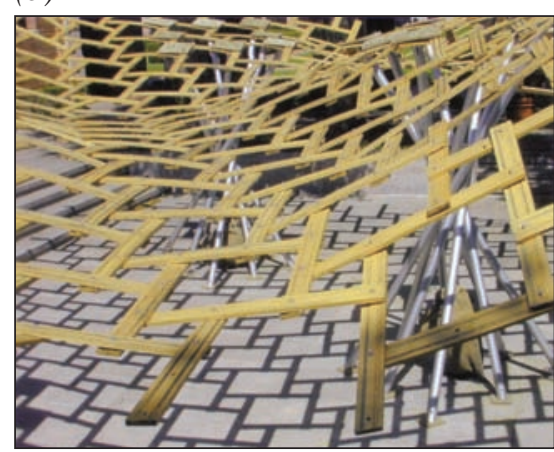

Fig. 3: Contemporary applications of reciprocal frames: (a) Bunraku puppet theatre (Kazuhiro Ishii, 1994) and (b) Forest Park pavilion in St Louis (Shigeru Ban and Cecil Balmond, 2007) by walls or columns. When the spans were larger, it was necessary to use special larger beams, which were difficult to obtain, expensive and inconvenient to transport and to erect on site. Alternative solutions to cover large spans had therefore been investigated. In this sense, reciprocal grillage structures, as proposed in Ref. [4], allowed to cover large spans with short elements.

Oriental architecture also developed similar principles of reciprocity structures, related to timber construction as well. In this case, however, its application derived from different inspirational concepts, mostly related to symbolic magical and religious geometries or patterns.

More recently, in the past decades, several reciprocal frame structures 
have been built, most of them as regular spatial configurations in timber construction, mainly in Japan and in the UK. ${ }^{4,7}$ In addition, several experimental structures, such as Pizzigoni's proposal for the Italian pavilion at the 2010 World Expo at Shanghai, ${ }^{8}$ the temporary pavilion Forest Park at St Louis, ${ }^{9}$ by Shigeru Ban and Cecil Balmond, or the Weave bridge at Pennsylvania University, also by Cecil Balmond (Fig. 3), have been designed or constructed. These experimental projects have been executed in an academic environment, related to teaching or research practices. These projects evidenced an increasing interest in the morphology, geometry and structural behaviour of reciprocal frames. ${ }^{10-13}$

\section{Euskalduna's Reciprocal Frame: Configuration, Analysis and Construction Specificities}

The roof structure of the Euskalduna extension, configured as a reciprocal frame, had to respond to several requirements and intentions. First of all, it had to adapt to irregular floor plan geometry and to reflect visual continuity or irregularity, in accordance with architectural intentions.

Besides, the configuration of the reciprocal frame and the layout of the structural elements had to be coordinated with the interior organisation and distribution of the space. In particular, the roof structure had to consider the hanging of sliding cladding panels in the perimeter of specific areas (concert hall, VIP lounge and services areas) to eventually close them. Also in the outer perimeter of the building, the layout of the structural elements had to be adjusted according to the layout of the facade. The facade is set back with respect to the roof perimeter; therefore, several elements of the roof structure had to be disposed in cantilever. In these cases, it is required to consider continuous joints for the cantilever elements, locally distorting the behaviour of the reciprocal frame structure.

Finally, due to the marked difference in ground levels between the access from Abandoibarra Avenue and the esplanade, the roof was set up in two inclined plans. Additionally, several structural elements were required to reduce its thickness in order to satisfy the requirements of interior height.

Taking into account all these issues, as well as the structural requirements, a complex process was held to define the structural configuration, as an irregular reciprocal frame, and the sizing of elements. It is important to highlight the importance of con ritit ring simultaneously both the otiuctural configuration and the sizing of the different elements, as a minor change in one of them may hava greater impact on the other.

The result was a complex irregular reciprocal frame that covered a maximum span of about $45 \mathrm{~m}$, with structural elements shorter than $20 \mathrm{~m}$. The elements' layout and the structural configuration being very irregular, there was a great difference between the loads carried and the span covered by the different elements. Eight different types of structural elements were therefore considered, in accordance with their efforts, from standard IPE 400 profiles to cellular beams of $1,0 \mathrm{~m}$ thickness and to plane or spatial trusses of 2,0 m thickness (Fig. 4). This diversity of elements allowed optimisation of both the behaviour and the self-weight of the structure. It also added a degree of complexity in its perception that suited well to the architectural intentions of irregularity and complexity.

Considering the behaviour of the structure as a reciprocal frame, several issues can be highlighted, regarding the general principles of reciprocal frames, as well as those particular to this structure.

First of all, it is a plane reciprocal frame, and thus, elements are mainly subject to bending moments, instead of axial forces, as would be the case in a spatial reciprocal frame. Its configuration is irregular, which means the different elements of the structure are not identical as in regular reciprocal frames. In addition, the progression of the load transfer is not cyclical but mainly diffused, with little concatenations with itself of the different elements. ${ }^{12}$

A characteristic feature of irregular reciprocal frames, which is especially

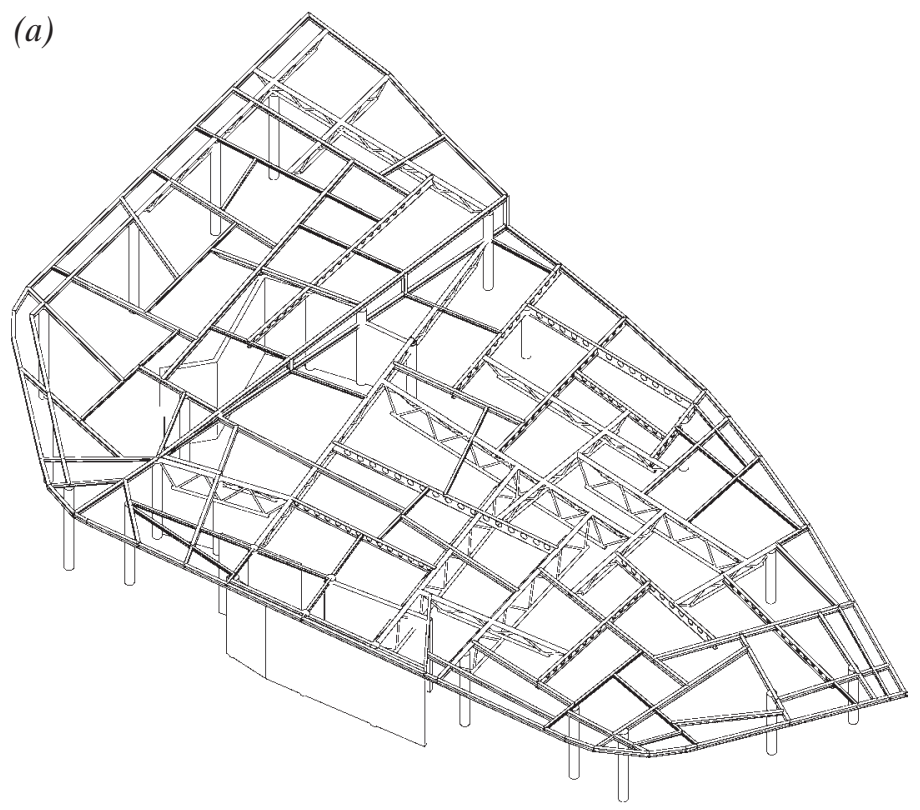

(b)

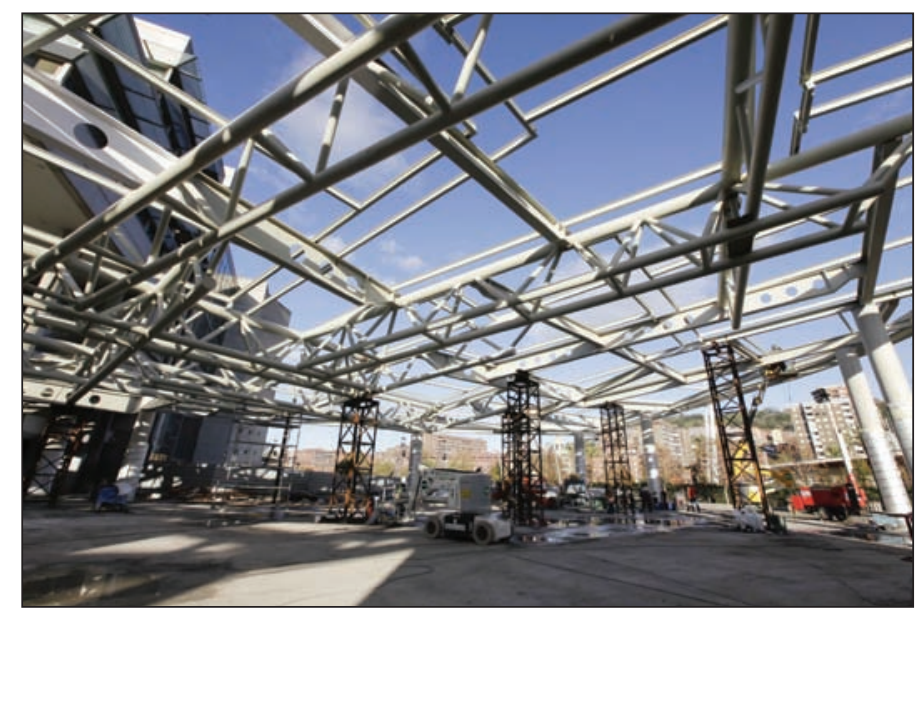

Fig. 4: (a) General 3D view of the structural configuration and different types of elements considered; (b) structure under construction, with temporary props 


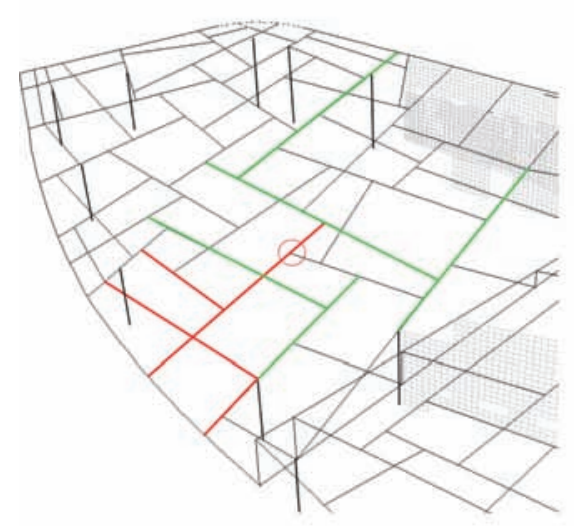

Elements modified from cases A to B:

Red: increase size

Green: reduce size

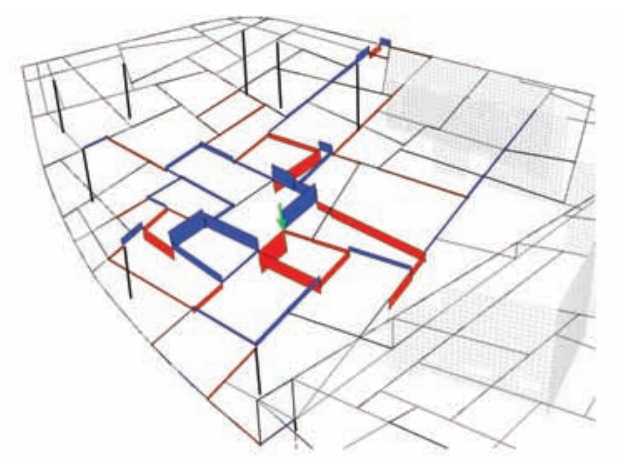

Case A. Shear stresses

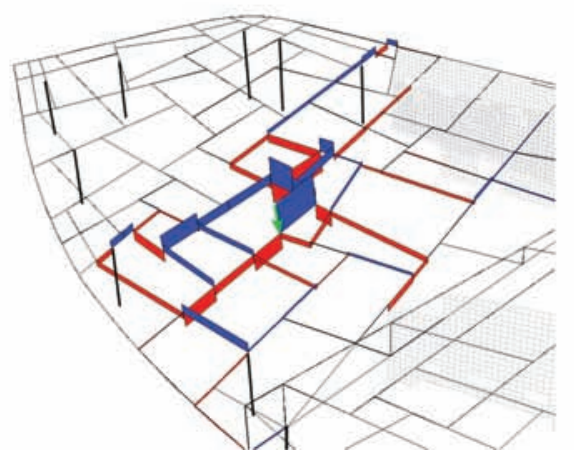

Case B. Shear stresses

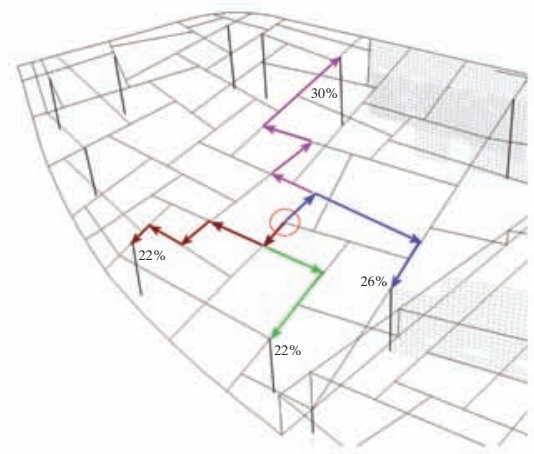

Case A. Load paths

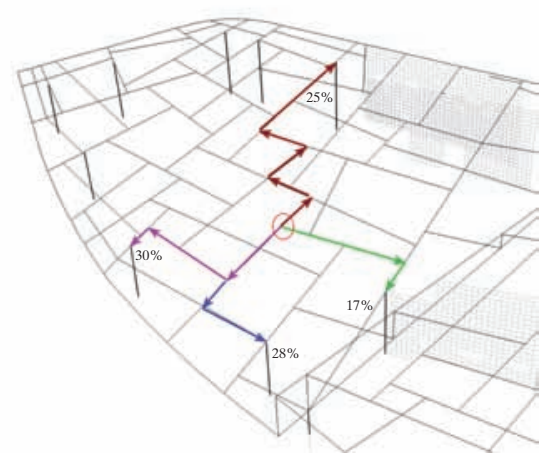

Case B. Load paths

Fig. 5: General view of the analysis model. Establishment of different load paths by modifying the rigidity of the structural elements

evident in this case, is the existence of a certain hierarchy in the structure. Each element covers a particular span and is sized distinctively according to its efforts. The rigidity of each element is therefore different, and a structural hierarchy is established, with elements that are more rigid acting as the primary elements and those where the rigidity is lower as secondary or tertiary elements. However, the resulting structural hierarchy is very irregular and variable, in the sense that a minor change either in the configuration of the reciprocal frame or in the size of an element might have a great impact on the resulting load paths, modifying the hierarchy of the different elements. This process of modification of the load paths is not easy to predict but was nevertheless very important during the process of configuration and sizing of the structure. For instance, it allowed reduction of the thickness of the structural elements where required, by controlling and modifying the load paths to reduce the efforts in particular elements. As an example of this process, it has been shown in Fig. 5 how the load path changes when the sizing of certain elements is modified. From cases A to B, elements highlighted in red increased its size, while that of those highlighted in green reduced in the same proportion. When the sizing of an element is increased, its stiffness increases and therefore attracts a major percentage of the loads, guiding the load path through it.

Another important issue to highlight is the large deformatility of reciprocal frames that accumulate the deflection of each elemest of the load path throughout the entire system. In this case, being areof structure, the requirements in terms of deformability were not very restrictive, but this may be a very limitative characteristic of reciprocal frames if applied to floor slabs.

Finally, from a constructive point of view, there are three main issues that characterise frame structures. First, the moderate length of the elements, allowing in this case to cover spans of almost $50 \mathrm{~m}$ with elements shorter than $20 \mathrm{~m}$. This is very advantageous in terms of transport and assembly on site.

Besides, configuration of reciprocal frames is based on the direct support of each element in others and connections do not need to transfer bending moment efforts. This was especially relevant in this project, with very different types and sizes of elements, allowing the connections to be designed as simply welded on site shear-only connections.

Finally, configuration of reciprocal frames as a set of self-supported elements requires the system to be completely erected to guarantee its stability. In this sense, intermediate construction stages have to be considered and analysed, disposing temporary props in strategic locations to support the structure until the reciprocal frame is complete. Eight intermediate temporary props were disposed during the erection and assembly stages. They reduced the maximum span covered by steel elements at these intermediate stages, controlling both efforts and deflection until the entire system was complete and its reciprocal frame behaviour was assured (Fig. 4).

\section{Conclusion}

The roof structure of the Euskalduna conference centre and concert hall extension, spanning $45 \mathrm{~m}$, is one of the largest reciprocal frame structures built in the world. As a reference, the maximum span covered by reciprocal frame wood structures, in projects such as the Stonemason Museum or St. Louis Forest Park pavilion, is lower than $30 \mathrm{~m} .{ }^{4}$ Besides, to the knowledge of the authors, there is no important reciprocal frame structure built in steel. In this sense, Euskalduna's reciprocal frame structure is a very particular one because of the material used (steel), its extremely irregular configuration and the different sizing of the structural elements (Fig. 6)

It shows the structural and architectural possibilities of irregular frame 

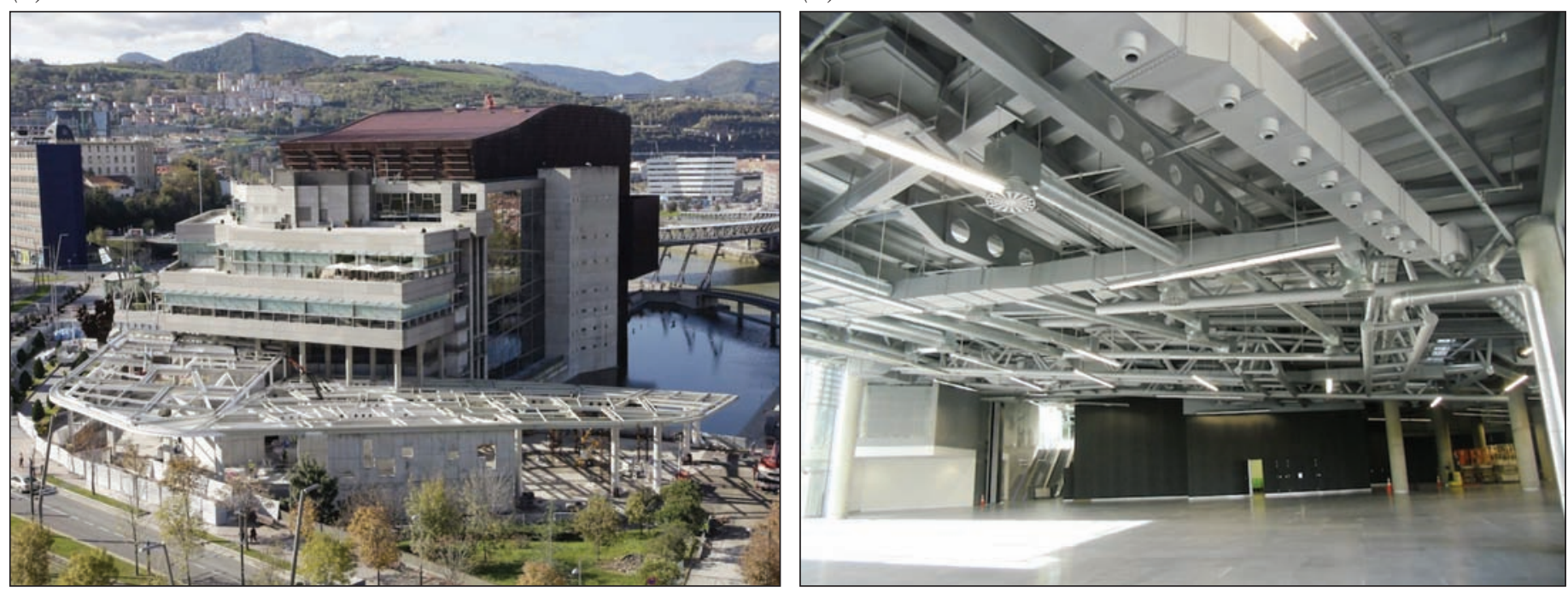

Fig. 6: Euskalduna reciprocal frame structure finished (a) Exterior view before placing of the roof panels (b) Interior view completely finished

structures, allowing easy accommodation to complex floor-plan geometries and promoting the bi-directionality and continuity of the system. However, it is important to note that the requirements and architectural intentions of this project were very particular, and the configuration of an irregular frame structure suited well to respond to them. But this kind of systems might result in extremely and needlessly complex and chaotic structures, if the project conditions were not clearly suitable to integrate them.

Finally, as a result of this study, two interesting issues may be highlighted as further research fields: the static analysis of irregular frame structures and the definition and analysis of intermediate construction stages of reciprocal frames.

\section{References}

[1] Ibáñez M, Ibarra JLY, Zabala M. Euskalduna. Del astillero al Palacio de congresos y de la música. Diputación Foral de Bizkaia; 2004.

[2] Soriano F, y Palacios D. El buque fantasma... de Wagner, naturalmente. Colección exjertos $\mathrm{C}$. Fisuras de la cultura contemporánea: Madrid; 2000.

[3] Bernabeu A, García D. Cubierta de la ampliación del palacio Euskalduna en Bilbao: una aplicación contemporánea de las estructuras recíprocas. $\mathrm{V}$ Congreso Iternacional de la Asociación Científica del Hormigón Estructural ACHE: Barcelona; 2011.

[4] Popovic Larsen O. Reciprocal Frame Architecture. ArchitecturaL Press: Amsterdam; 2008.

[5] Pugnale A, Parigi D, Sassone M, Kirkegaard $\mathrm{PH}$. The principle of structural reciprocity: history, properties and design issules. Proceedings of the IABSE-IASS Sympoivin 2001: Taller, Longer, Lighter, London, 20-23 September 2011.

[6] Chilton JC, Chos BS. Reciprocal frame long span structures. In Innovative Large Span Structures, En rivasta NK, Sherbourne AN, Roorda J (eds). Canadian society for Civil Engineerin, Toronto; 1992; 100-109.

[7] Chilton JC. Development of timber reciprocal frame structures in the UK. Proceedings of the International Association for Shell and Spatial Structures (IASS) Symposium 2009. Valencia, 28 septiembre - 2 de octubre: 1877-1884.

[8] Pizzigoni A. Le strutture spaziali resiproche 17 Congresso Collegio dei Tecnici della Industrializzazione Edilizia CTE. Roma, 5-8 noviembre 2008 .

[9] VVAA, "Cecil Balmond" A+U Architecture, noviembre 2006 , special issue.

[10] Sánchez J, Escrig F, y Rodríguez M T. Una aproximación analítica a las mallas recíprocas diseñada por Leonardo Informes de la Construcción 2010; 62(518): 5-14.

[11] Chilton JC, Choo BS, Popovic O. Reciprocal Frames past, present and future. In Proceedings of the International Conference in Lightweight Structures in Civil Engineering. In Obrebski, JB (ed), Magat Magdalena Burska: Warsaw; 1995; 26-29.

[12] Kohlhammer T, Kotinik T. Systemic behaviour of plane reciprocal frame structures. Struct. Eng. Int. 2011; 1: 80-86.

[13] Parigi D, Sassone M, Napoli P. Kinematic and static analysis of plane reciprocal frames Proceedings of the International Association for Shell and Spatial Structures (IASS) Symposium 2009. Valencia, 28 septiembre - 2 de octubre, 1885-1894.

\section{SEI Data Block}

Owner:

Euskalduna Jauregia

Contractor:

UTE Euskalduna (José Antonio

Olabarri SL, Construcciones Lauki,

Pabisa, Grupo Inbisa)/Steel structure:

Goros S. Coop

\section{Architect:}

Soriano y Asociados (Federico

Soriano, Dolores Palacios)

Consulting engineer:

IDOM

Steel $(\mathrm{t})$ :

Estimated cost (USD million):

Service date:

May 2012 